\title{
A Genetic Locus Associated with Resistance to Fusarium oxysporum f. sp. niveum Race 2 in Citrullus lanatus-type Watermelon
}

\author{
Geoffrey Meru and Cecilia E. McGregor ${ }^{1}$ \\ Department of Horticulture, University of Georgia, Athens, GA 30602
}

\begin{abstract}
AdDitional INDEX wORDs. fusarium wilt, single nucleotide polymorphism, genotyping by sequencing, quantitative trait locus
Abstract. Fusarium wilt of watermelon (Citrullus lanatus), caused by Fusarium oxysporum f. sp. niveum (FON), is a devastating soil-borne disease limiting watermelon production across the world. Although many watermelon cultivars have been bred for resistance to FON races 0 and 1, the only released cultivars that are resistant to FON 2 are nonharvested pollenizers. The lack of FON 2-resistant edible cultivars is thought to be associated with linkage drag and/or preferential inheritance patterns observed when crossing the resistant, wild source (Citrullus amarus), with edible watermelon. A potential way to overcome these obstacles is to use a resistant $C$. lanatus as the source of resistance and to develop molecular markers to increase the efficiency of selection. Here we describe the identification of a quantitative trait locus (QTL) associated with FON 2 resistance in watermelon. The genotyping by sequencing (GBS) platform was used to generate single nucleotide polymorphisms $\left(\right.$ SNPs) in an $F_{2}$ population $(n=178)$ developed from a cross between UGA147 (resistant) and 'Charleston Gray' (susceptible). Five hundred and one SNPs were placed on the watermelon physical map and used in the mapping of QTL. $F_{3}$ lines were phenotyped for resistance to FON 2 in the greenhouse. An intermediate QTL associated with resistance to FON 2 was identified on chromosome 11 (Qfon11). This QTL is a potential target for marker-assisted selection (MAS) for FON 2 resistance in watermelon.
\end{abstract}

Watermelon is a widely cultivated crop of the Cucurbitaceae family, popular for its sweet flesh and edible seeds (AchiganDako et al., 2008; Edelstein and Nerson, 2002; Robinson and Decker-Walters, 1997). The intense selection during watermelon domestication has led to low genetic diversity in the cultivated genotypes (Guo et al., 2013; Hawkins et al., 2001a; Levi et al., 2001). Genome sequencing of wild and cultivated Citrullus detected a loss of disease resistance genes in cultivated material (Guo et al., 2013). Therefore, watermelon crop wild relatives [CWR (Maxted et al., 2006)] are expected to be useful sources of pest and disease resistance for watermelon cultivar development. Indeed, numerous studies have identified resistance to watermelon pests and diseases in CWR (Boyhan et al., 1992, 1994; Davis et al., 2007; Gusmini et al., 2005; Netzer and Martyn, 1989; Sowell, 1975; Sowell et al., 1980; Strange et al., 2002; Tetteh et al., 2010; Thies and Levi, 2007; Wechter et al., 2012a). However, the incorporation of resistance loci from CWR is not without obstacles.

The use of CWR in breeding is hampered by their poor agronomic traits, which can make the process of incorporating desired genes into elite material, without introgressing unwanted genes, long and tedious. For watermelon, there have been numerous efforts to incorporate disease resistance from C. amarus [previously C. lanatus var. citroides (Chomicki and Renner, 2015; Paris, 2015)] into elite material. The efforts associated with introgressing fusarium wilt resistance have

Received for publication 1 Aug. 2016. Accepted for publication 18 Oct. 2016. This research was supported in part by a U.S. Department of Agriculture Research and Education grant (GEO-2009-04819) and a U.S. Department of Agriculture Specialty Crop Research Initiative grant (2014-51181-22471).

Current address: Tropical Research and Education Center/Institute of Food and Agricultural Sciences, University of Florida, 18905 SW 280th Street, Homestead, FL 33031.

${ }^{1}$ Corresponding author. E-mail: cmcgre1@uga.edu. been particularly successful on one hand (race 1), and frustrating on the other (race 2).

Fusarium oxysporum f. sp. niveum is a soil-borne pathogen that causes vascular wilting in watermelon, often resulting in yield reduction and crop failure (Everts and Himmelstein, 2015; Martyn, 2014). Four FON races have been described $(0,1,2$, and 3$)$ based on their virulence or the ability to overcome specific resistance in a set of differential cultivars (Bruton et al., 2007, 2010; Egel et al., 2005; Zhou et al., 2010). The ability of the pathogen's chlamydospores to persist in the soil for a long time, combined with the rapid evolution of its races has rendered the management of fusarium wilt difficult. Until recently, soil fumigation with methyl bromide was a popular management practice for fusarium wilt; however, this chemical has been phased out due to environmental concerns. The use of resistant cultivars is the most preferred management method for fusarium wilt (Bruton et al., 2007; Martyn and Netzer, 1991; Zhou and Everts, 2001). Since William Orton developed the first fusarium wilt resistant cultivar, Conqueror, using a wild $C$. amarus as the resistance source (Orton, 1907, 1917), numerous cultivars with resistance to FON races 0 and 1 have been developed (Martyn, 2014 for review). In particular, the resistance to FON 1 in the cultivar Calhoun Gray has been extensively used in watermelon breeding and many modern cultivars contain this resistance (Everts and Himmelstein, 2015). Several recent molecular studies have shown that $F_{O}-1$ is associated with a major QTL (Qfon 1.1; $R^{2}=23 \%$ to $60 \%$ ) on chr. 1 (Lambel et al., 2014; Meru and McGregor, 2016; Ren et al., 2015) of the watermelon draft genome (Guo et al., 2013).

High resistance to FON races 0,1 , and 2 was described in 1991 in PI 296341-FR (Martyn and Netzer, 1991; Zhang and Rhodes, 1993). Resistance to FON 1 in PI 296341-FR is reported to be associated with the same QTL region on chr. 1 (Qfon 1.1) that confers resistance in 'Calhoun Gray' (Ren et al., 
2015). Resistance to FON 2 in PI 296341-FR is thought to be polygenic and controlled by at least a pair of recessive genes in epistasis with other minor genes (Martyn and Netzer, 1991; Zhang and Rhodes, 1993). Two QTL, one on chr. $9\left(R^{2}=\right.$ $13.7 \%)$ and the other on chr. $10\left(R^{2}=12.5 \%\right)$ are associated with this resistance (Ren et al., 2015). Despite the identification of PI 296341-FR as a source of resistance to FON 2 more than 25 years ago, there are no sweet-fleshed watermelon cultivars with resistance to FON 2 currently available to growers, likely due to a combination of linkage drag, the genetic background of the donor, and the quantitative nature of the resistance. PI 296341-FR is a selection from a C. amarus accession with hard, nonsweet, white flesh (Martyn and Netzer, 1991). Severe segregation distortion, including preferential inheritance of $C$. amarus alleles (Hawkins et al., 2001b; Levi et al., 2011; McGregor and Waters, 2013; Sandlin et al., 2012) and low pollen fertility (McGregor and Waters, 2013) have been observed in crosses between $C$. lanatus and watermelon.

The resistance from PI 296341-FR has been incorporated into the nonharvested Super Pollenizer ${ }^{\mathrm{TM}}$ series from Syngenta (Syngenta Seeds Inc., 2009), but efforts to introgress the resistance into sweet, edible cultivars have not been successful to date. The lack of success incorporating resistance from PI 296341-FR suggests that breeders face serious challenges when incorporating quantitative traits, not associated with major QTL, from C. amarus into elite germplasm.

Additional sources of FON 2 resistance have been described in C. amarus (Boyhan et al., 2003; Dane et al., 1998; Martyn and Netzer, 1991; Wechter et al., 2012a, 2012b). Generally, the basis of these resistances are not well understood, but is thought to also be polygenic. It remains to be seen whether resistance introgression from these accessions will face the same challenges as PI 296341-FR.

One way to circumvent the challenges encountered with resistance introgression from C. amarus, is to introgress resistance from a source genetically closely related to the elite watermelon material. Boyhan et al. (2003) identified a number of watermelon accessions in the U.S. Department of Agriculture (USDA) germplasm collection with resistance to FON 2 with pink or red flesh (USDA, 2016). These accessions provide a potential path to FON 2 resistance introgression circumventing the problems associated with introgression from C. amarus. The efficiency of trait introgression can also be improved by the use of MAS. The first step toward the use of MAS for quantitative traits is to identify loci associated with the trait of interest. The aim of the current study was therefore to identify QTL associated with FON 2 resistance in a watermelon accession of the C. lanatus type.

\section{Materials and Methods}

Plant material and DNA extraction. The FON 2 resistance source used in this study is UGA147, a resistant selection originating from PI 169233 (Boyhan et al., 2003). UGA147 has variable pink and yellow flesh color and soluble solids concentration (SSC) between $7 \%$ and $8 \%$. A cross was made in the greenhouse between UGA147 and 'Charleston Gray' (susceptible). A single $F_{1}$ plant was selfed to yield $F_{2}$ plants which were further selfed to generate $178 \mathrm{~F}_{2: 3}$ families. DNA was extracted from leaf material of the parents, the $F_{1}$ and each of the $F_{2}$ plants using the E.N.Z.A 96-well format kit (Omega Bio-tek, Norcross, GA) according to the manufacturer's instructions. The concentration and quality of the DNA was determined by absorbance measurements
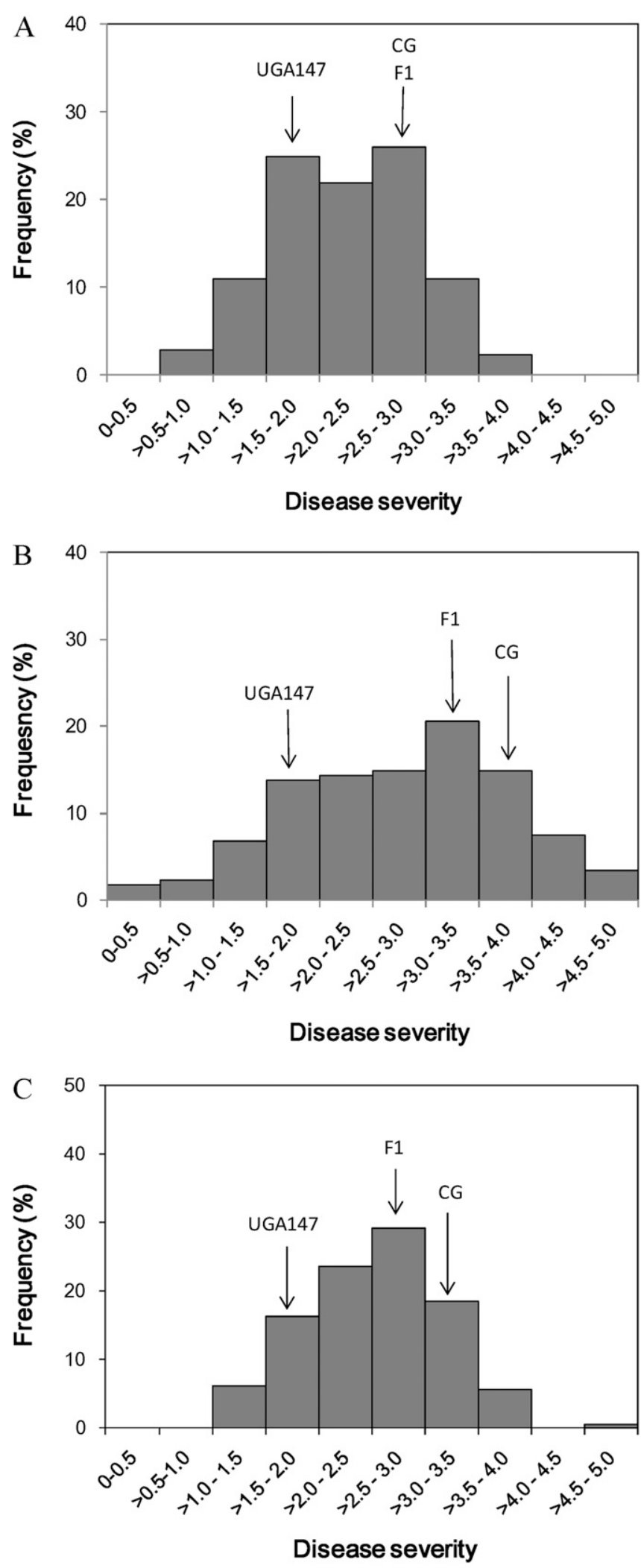

Fig. 1. Frequency distribution for disease severity at $26 \mathrm{~d}$ after inoculation for the (A) April, (B) July, and (C) joint screening of the 'Charleston Gray' (CG) $\times$ UGA147 $\mathrm{F}_{2: 3}$ watermelon population with Fusarium oxysporum f. sp. niveum race 2 . Disease severity was visually rated on a scale of 0 to 5 where, $0=$ asymptomatic plants, $1=$ initial wilting on one leaf, $2=$ continued wilting in more than one leaf, $3=$ all leaves wilted, $4=$ all leaves wilted and stem collapsing, and $5=$ dead plants (Meru and McGregor, 2016). 
(Infinite M200 PRO; Tecan Group, Männedorf, Switzerland) and by agarose gel electrophoresis. To ensure that the quality of the extracted DNA was sufficient for digestion with restriction enzymes, samples of the DNA extracted were digested using EcoRI (New England Biolabs, Ipswich, MA).

GBS, SNP ANALYSIS, AND MAP CONSTRUCTION. Genotyping of the parents, $F_{1}$ and $178 F_{2}$ plants was carried out using GBS (Elshire et al., 2011) at the Institute for Genomic Diversity (IGD), Cornell University, Ithaca, NY. The DNA was digested using ApeKI-restriction enzyme and fragment alignment and SNP calling performed using the GBS reference pipeline in TASSEL, version 3.0.160 (Bradbury et al., 2007. The watermelon draft genome from cultivar 97103 was used as a reference genome (Guo et al., 2013). The generated SNP calls in HapMap format provided by IGD were filtered in Excel (Microsoft, Redmond, WA) for missing data (with up to $70 \%$ missing data), polymorphism between the mapping population parents and segregation distortion $(P<0.00001)$. Based on this criterion, 501 SNPs were placed on the physical map (Guo et al., 2013) and used for QTL mapping. Meru and McGregor (2016) previously showed that comparable results were obtained when using the physical (markers ordered according to their physical positions) or genetic map to identify QTL associated with FON 1 resistance in watermelon.

Fungal INOCULUM PREPARATION. FON 2 (isolate 04-04122, provided by B. Bruton), was grown (14/10 h dark cycle) on quarter-strength potato dextrose agar (Becton, Dickinson and

Table 1. The length in megabases of each chromosome and the corresponding number of single nucleotide polymorphisms identified on the physical map in the $\mathrm{F}_{2}$ watermelon population developed from a cross between 'Charleston Gray' and UGA147.

\begin{tabular}{lcc}
\hline & \multicolumn{2}{c}{ Physical map } \\
\cline { 2 - 3 } Chromosome no. & 40 & Length (Mbp) \\
\hline 1 & 43 & 34.05 \\
2 & 27 & 30.55 \\
3 & 23 & 27.93 \\
4 & 59 & 23.66 \\
5 & 64 & 33.31 \\
6 & 51 & 26.94 \\
7 & 45 & 29.57 \\
8 & 58 & 25.09 \\
9 & 44 & 34.89 \\
10 & 47 & 28.15 \\
11 & 501 & 26.77 \\
Total & & 320.98 \\
\hline
\end{tabular}

Company, Franklin Lakes, NJ) for $12 \mathrm{~d}$ and 1-cm² agar plugs were transferred into $250-\mathrm{mL}$ erlenmeyer flasks containing 100-mL potato dextrose broth (Becton, Dickinson and Company). The fungal cultures were grown (14/10 h light/dark cycles) on a shaker (Mini-Orbital; Henry Troemner, Thorofare, NJ) at $200 \mathrm{rpm}$ for $10 \mathrm{~d}$ and the inoculum filtered through four layers of sterile cheese cloth. The microconidial concentration was determined using a hemacytometer (Hausser Scientific, Horsham, PA) and adjusted accordingly using sterile water.

Phenotyping. Disease screening was carried out in the greenhouse in Apr. 2014 and in July of the same year. In addition to the parental materials ('Charleston Gray' and UGA147), the $\mathrm{F}_{1}$ and $178 \mathrm{~F}_{2: 3}$ lines, the following controls were included: 'Sugar Baby' (susceptible), 'Calhoun Gray' (susceptible), 'SP-6' [resistant (Syngenta, Basel, Switzerland)], and USVL252-FR2 [resistant (Wechter et al., 2012b)]. Disease screening experiments were performed as described previously for QTL mapping of FON 1 resistance (Meru and McGregor, 2016), but using a spore concentration of $5 \times 10^{5}$ spores $/ \mathrm{mL}$. The lower spore concentration was used to slow down disease development to improve discrimination among $\mathrm{F}_{2: 3}$ lines. Briefly, watermelon seeds were sown in cells $(5.98 \times 3.68 \times 4.69 \mathrm{~cm})$ filled with steam-pasteurized sand:peat:vermiculite (4:1:1) amended with $14 \mathrm{~N}-4.2 \mathrm{P}-11.6 \mathrm{~K}$ controlled-release fertilizer (Osmocote; Scotts, Marysville, $\mathrm{OH})$. At the first true leaf stage, the cell trays with seedlings were immersed in inoculum contained in plastic tubs for $15 \mathrm{~min}$. For each disease screening experiment, four seeds of each cultivar/line were sown per replication with a total of three inoculated replications in a randomized complete block design. One additional replication was mock inoculated.

Plants were evaluated $26 \mathrm{~d}$ after inoculation for symptom severity on a scale of 0 to 5 with a score of 0 representing asymptomatic plants, a score of 1 for plants showing initial wilting on one leaf, a score of 2 for plants showing continued wilting in more than one leaf, a score of 3 for plants with all the leaves wilted, a score of 4 for plants with all leaves wilted and stem collapsing, and a score of 5 for dead plants (Meru and McGregor, 2016). Pearson pairwise correlations ( $r$ ), Spearman rank order correlation $\left(r_{\mathrm{s}}\right)$, and the Shapiro and Wilk test for normality (Shapiro and Wilk, 1965) were calculated in $\mathrm{JMP}^{\circledR}$ Pro (version 12.1.0; SAS Institute, Cary, NC).

QTL DETECTION. The detection of QTL was performed using composite interval mapping (CIM) with a $10-\mathrm{cM}$ window in WinQTL Cartographer, version 2.5 (Wang et al., 2011) and a walk speed of $1 \mathrm{cM}$. The standard model (Model 6) was used for CIM analysis and the statistical significance of a QTL determined by likelihood-odds (LOD) thresholds set by 1000

Table 2. The megabase position of the quantitative trait locus associated with resistance to Fusarium oxysporum f. sp. niveum race 2 and the corresponding 2-likelihood-odds (LOD) support interval for separate and joint data for disease severity observed at $26 \mathrm{~d}$ after inoculation from two screens of the 'Charleston Gray' $\times$ UGA147 $\mathrm{F}_{2: 3}$ watermelon population.

\begin{tabular}{|c|c|c|c|c|c|c|c|c|}
\hline Screen & Chr. & Position $(\mathrm{Mbp})^{\mathrm{z}}$ & LOD $^{y}$ & $R^{2}(\%)^{\mathrm{x}}$ & Additive effect ${ }^{\mathrm{w}}$ & Dominance effect ${ }^{\mathrm{w}}$ & $\begin{array}{l}\text { LOD-2 support } \\
\text { interval (Mbp) }\end{array}$ & $\begin{array}{l}\text { LOD-2 support } \\
\text { interval (Mbp) }\end{array}$ \\
\hline April & 11 & 22.81 & 3.89 & 9.6 & -0.24 & 0.10 & 22.4 & 23.9 \\
\hline July & 11 & 22.81 & 4.42 & 11.8 & -0.34 & 0.39 & 21.7 & 23.9 \\
\hline
\end{tabular}

${ }^{\mathrm{z}}$ The position of the quantitative trait loci on the chromosome (Guo et al., 2013).

${ }^{\mathrm{y}} \log _{10}$ likelihood ratio.

xPhenotypic variation explained.

wegative values indicate that the effect is contributed by the allele from the resistant parent (UGA147). 
permutations $(\alpha=0.05)$ (Churchill and Doerge, 1994). The QTL was visualized using MapChart 2.2 (Voorrips, 2002).

\section{Results and Discussion}

Phenotypic analysis. The distribution of the $\mathrm{F}_{2: 3}$ progeny in both screens fit a normal distribution (Fig. 1). Symptom development in the April screen was less severe (mean disease score in $\mathrm{F}_{2: 3}$ population 2.27 , mean of controls $=2.4$ ) than the symptom development in the July screen (mean disease score in $\mathrm{F}_{2: 3}$ population 3.82 , mean of controls $=3.20$ ). The joint (averaged over both screens) disease severity score for UGA147 was 1.9, whereas the joint score for 'Charleston Gray' was 3.4 (Fig. 1). This was consistent with the scores of the other resistant ('SP-6' $=2.0$ and USVL252-FR2 = 2.3) and susceptible controls ('Sugar Baby' $=3.8$ and 'Calhoun Gray' = 3.4). It should be noted that the averages for USVL252-FR2 was skewed higher by a small number of individual plants that succumbed to disease while the majority were very resistant (data not shown), suggesting that this line was still segregating for resistance. The $\mathrm{F}_{1}$ plants (3.0) were intermediate, but skewed toward the susceptible parent (Fig. 1). Transgressive segregation was observed in both directions (more resistant than resistant parent and more susceptible than susceptible parent) (Fig. 1).

The correlation between the two screens for the population was low $(r=0.18)$, but still significant $(P<0.05)$. This correlation is lower than what was observed for FON 1 screening ( $r=0.63$ to 0.70 ) using the same methodology (Meru, 2014). This difference may be due to the genetic control of the traits. FON 1 is controlled by a major gene and therefore a smaller number of $\mathrm{F}_{2: 3}$ plants are needed to give an accurate estimate of the $\mathrm{F}_{2: 3}$ family means, whereas FON 2 is thought to be controlled by multiple genes with small effects, which would require a larger number of $\mathrm{F}_{2: 3}$ plants. Therefore, the 12 plants per line in the individual screens might not be large enough to get an accurate estimation of the family mean for FON 2 in the individual screens. If this is the case, one would still expect the correlation between the controls to be high. The calculated correlation between disease severity scores of the control cultivars was indeed high $\left(r_{\mathrm{s}}=0.71\right)$, but nonsignificant, possibly due to the small sample size $(n=7)$. Unfortunately, other FON QTL mapping studies in watermelon used only single phenotypic screens (Lambel et al., 2014; Ren et al., 2015), so it is not possible to reach a definitive conclusion regarding the repeatability of FON screens and its effect on QTL identification. We therefore present QTL mapping results from both separate and joint analysis.

GBS, SNP ANALYSIS, AND MAP CONSTRUCTION. In this study, GBS analysis generated a total of 1,963,049 tags of which $1,604,031(81.7 \%)$ aligned to unique positions, $85,763(4.4 \%)$ aligned to multiple positions, whereas $273,255(13.9 \%)$ could not be aligned to the watermelon reference genome (Guo et al., 2013). The number of tags generated with ApeKI restriction enzyme exceeded those generated from elite $\times$ elite $\mathrm{F}_{2}$ populations by Lambel et al. [2014 (527,844 tags)] and Meru and McGregor [2016 (933,662 tags)] with the same enzyme.

Analysis of the tags aligning to unique positions revealed 23,286 HapMap SNP calls, a number similar to that $(20,889)$ reported by Meru and McGregor (2016) in a $F_{2}$ population generated from a cross between 'Calhoun Gray' and 'Sugar Baby'. Of the 23,286 SNPs, 30.78\% (7165) were found to be polymorphic between UGA147 and 'Charleston Gray'. The number of polymorphic SNPs in this study is higher than that [28.66\% (5986)] found between 'Calhoun Gray' and 'Sugar Baby' (Meru and McGregor, 2016). The difference in the number of polymorphic SNPs between the two studies is expected because UGA147 × 'Charleston Gray' represents a wider cross than 'Calhoun Gray' $\times$ 'Sugar Baby' cross.

The 23,286 HapMap SNP calls were filtered according to missing data points, polymorphism between mapping population parents and segregation distortion. Polymorphic SNPs with up to $70 \%$ missing data and segregation distortion $(P<$ $0.00001)$ were allowed on the physical map to ensure good coverage of the genome. As expected with the GBS method, large amounts of missing data were observed due to low coverage of reads resulting from pooling of samples in a single sequencing lane (Barba et al., 2014). Following the described criterion, 501 SNPs were placed onto the physical map (Table 1) and used for QTL mapping (Meru and McGregor, 2016).

QTL DeTECTION. Data for the two screens were mapped separately and jointly and consistently revealed the same intermediate QTL associated with resistance to FON 2 on chr.11 (Table 2; Fig. 2). The resistant allele was contributed by the resistant parent (UGA147) and explains a similar amount of phenotypic variation ( $R^{2}$ between $9.6 \%$ and $16.2 \%$ ) as the QTL for FON 2 resistance $\left(R^{2}\right.$ values of $12.5 \%$ and $\left.13.5 \%\right)$ reported

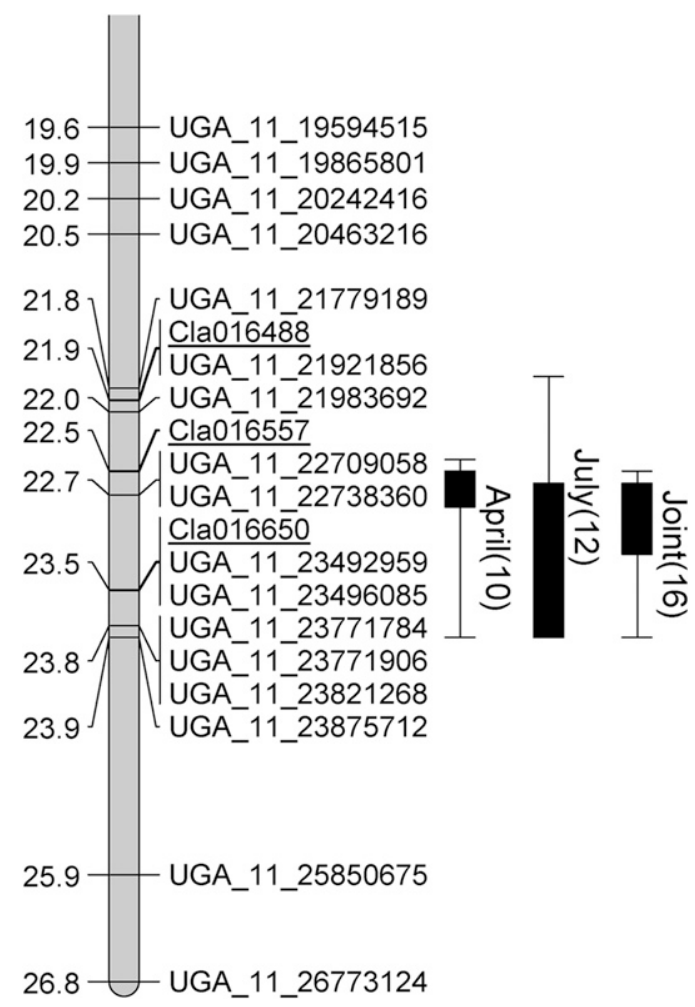

Fig. 2. Quantitative trait loci (QTL) associated with resistance to Fusarium oxysporum f. sp. niveum race 2 on chromosome chr. 11 identified by composite interval mapping in the 'Charleston Gray' $\times$ UGA147 $F_{2: 3}$ watermelon population. Data are for separate (April and July) and joint analysis of the two screens for $26 \mathrm{~d}$ after inoculation. The number in parenthesis after the QTL trait name is the percentage of phenotypic variation explained. The boxes represent the 1-likelihood-odds (LOD) interval and the whiskers the 2-LOD interval for QTL. The partial chromosome is shown and the numbers on the left correspond to the megabase position on the watermelon draft genome (Guo et al., 2013). The underlined locus names are resistance genes underlying the identified QTL. The figure was generated using MapChart, version 2.2 (Voorrips, 2002). 
in PI 296341-FR by Ren et al. (2015). The detection of QTL with minor and intermediate effects is common for disease resistance traits (Kou and Wang, 2010), and has been reported for Fusarium species infecting wheat [Triticum aestivum (Lv et al., 2014)] and chickpea [Cicer arietinum (Sabbavarapu et al., 2013)]. The size of the QTL effect identified in the current study underline the challenges breeders face when breeding for FON 2 resistance, since multiple loci will likely need stacking to obtain field level FON 2 resistance. The contribution of several QTL with small effect is also the probable reason why researchers have had difficulties fixing the resistance in PI 296341-FR (Everts and Himmelstein, 2015; Martyn, 2014; Zhao et al., 2005) and USVL252-FR2. We are observing similar results in our attempts to fix resistance in UGA147 (data not shown).

The chromosomal regions underlying the 2-LOD interval of the identified QTL contain several resistance genes (Fig. 2). Three receptor-like kinase pathogen-related genes, Cla016650, Cla016557, and Cla016488 (Guo et al., 2013), were found underlying the $Q$ fon 11 region. Receptor-like kinase genes play an important role in pathogen defense by acting as sentinels in both broad-spectrum and race-specific plant responses (Goff and Ramonell, 2007). These genes are potential candidates for investigation of the molecular mechanisms underlying resistance to FON 2 in watermelon.

UGA147 AS A SOURCE OF RESISTANCE TO FON RACE 2. The QTL identified in the current study accounts only for a small percentage of phenotypic variation observed in the population. This suggests that additional genetic factors, not identified in the current study, are involved in resistance against FON 2 in UGA147. Future research will include increasing the population size and advancing the population to recombinant inbred lines in an effort to identify such additional loci.

UGA147 is a potentially useful source of FON 2 resistance since it lacks many of the undesirable traits associated with $C$. amarus resistance sources. In addition to having a desirable pink-yellow flesh and moderate SSC, intraspecific crosses between UGA147 and elite material are easily accomplished, and progeny fertility appears normal. Therefore, it is expected that introgression of resistance loci from UGA147 will be less cumbersome than from other CWR sources.

\section{Literature Cited}

Achigan-Dako, E.G., R. Fagbemissi, H.T. Avohou, R.S. Vodouhe, O. Coulibaly, and A. Ahanchede. 2008. Importance and practices of egusi crops [Citrullus lanatus (Thunb.) Matsum. \& Nakai, Cucumeropsis mannii Naudin and Lagenaria siceraria (Molina) Standl. cv. 'Aklamkpa'] in sociolinguistic areas in Benin. Biotechnol. Agron. Soc. Environ. 12:393-403.

Barba, P., L. Cadle-Davidson, J. Harriman, J.C. Glaubitz, S. Brooks, K. Hyma, and B. Reisch. 2014. Grapevine powdery mildew resistance and susceptibility loci identified on a high-resolution SNP map. Theor. Appl. Genet. 127:73-84.

Boyhan, G., J.D. Norton, and B.R. Abrahams. 1994. Screening for resistance to anthracnose (race 2), gummy stem blight, and root knot nematode in watermelon germplasm. Cucurbit Genet. Coop. Rpt. 17:106-110.

Boyhan, G., J.D. Norton, B.J. Jacobsen, and B.R. Abrahams. 1992. Evaluation of watermelon and related germ plasm for resistance to zucchini yellow mosaic virus. Plant Dis. 76:251-252.

Boyhan, G.E., D.B. Langston, D.M. Granberry, P.M. Lewis, and D.O. Linton. 2003. Resistance to fusarium wilt and root-knot nematode in watermelon germplasm. Cucurbit Genet. Coop. Rpt. 26:18-25.
Bradbury, P.J., Z. Zhang, D.E. Kroon, T.M. Casstevens, Y. Ramdoss, and E.S. Buckler. 2007. TASSEL: Software for association mapping of complex traits in diverse samples. Bioinformatics 23:2633-2635.

Bruton, B.D., W.W. Fish, E. Vivoda, B. Gabor, and K.L. Everts. 2010. On the reliability of Fusarium oxysporum f.sp. niveum research: Do we need standardized testing methods? p. 222-225. In: J.A. Theis, C.S. Kousik, and A. Levi (eds.). Cucurbitaceae 2010 proceedings, ASHS Press, Alexandria, VA.

Bruton, B.D., W.W. Fish, X.G. Zhou, K.L. Everts, and P.D. Roberts. 2007. Fusarium wilt in seedless watermelons, p. 93-98. In: Proc. 2007 Southeast Regional Veg. Conf., Savannah, GA.

Chomicki, G. and S.S. Renner. 2015. Watermelon origin solved with molecular phylogenetics including Linnaean material: Another example of museomics. New Phytol. 205:526-532.

Churchill, G.A. and R.W. Doerge. 1994. Empirical threshold values for quantitative trait mapping. Genetics 138:963-971.

Dane, F., L.K. Hawkins, J.D. Norton, Y.-S. Kwon, and Y.-H. Om. 1998. New resistance to race 2 of Fusarium oxysporum f.sp. niveum in watermelon. Cucurbit Genet. Coop. Rpt. 21:37-39.

Davis, A.R., A. Levi, A. Tetteh, T. Wehner, V. Russo, and M. Pitrat. 2007. Evaluation of watermelon and related species for resistance to race $1 \mathrm{~W}$ powdery mildew. J. Amer. Soc. Hort. Sci. 132:790-795.

Edelstein, M. and H. Nerson. 2002. Genotype and plant density affect watermelon grown for seed consumption. HortScience 37:981-983.

Egel, D.S., R. Harikrishnan, and R.D. Martyn. 2005. First report of Fusarium oxysporum $\mathrm{f}$. sp. niveum race 2 as causal agent of fusarium wilt of watermelon in Indiana. Plant Dis. 89:108.

Elshire, R.J., J.C. Glaubitz, Q. Sun, J.A. Poland, K. Kawamoto, E.S. Buckler, and S.E. Mitchell. 2011. A robust, simple genotyping-bysequencing (GBS) approach for high diversity species. PLoS One 6:e19379.

Everts, K.L. and J.C. Himmelstein. 2015. Fusarium wilt of watermelon: Towards sustainable management of a re-emerging plant disease. Crop Prot. 73:93-99.

Goff, K.E. and K.M. Ramonell. 2007. The role and regulation of receptorlike kinases in plant defense. Gene Regul. Syst. Bio. 1:167-175.

Guo, S., J. Zhang, H. Sun, J. Salse, W.J. Lucas, H. Zhang, Y. Zheng, L. Mao, Y. Ren, Z. Wang, J. Min, X. Guo, F. Murat, B.-K. Ham, Z. Zhang, S. Gao, M. Huang, Y. Xu, S. Zhong, A. Bombarely, L.A. Mueller, H. Zhao, H. He, Y. Zhang, Z. Zhang, S. Huang, T. Tan, E. Pang, K. Lin, Q. Hu, H. Kuang, P. Ni, B. Wang, J. Liu, Q. Kou, W. Hou, X. Zou, J. Jiang, G. Gong, K. Klee, H. Schoof, Y. Huang, X. Hu, S. Dong, D. Liang, J. Wang, K. Wu, Y. Xia, X. Zhao, Z. Zheng, M. Xing, X. Liang, B. Huang, T. Lv, J. Wang, Y. Yin, H. Yi, R. Li, M. Wu, A. Levi, X. Zhang, J.J. Giovannoni, J. Wang, Y. Li, Z. Fei, and Y.Xu. 2013. The draft genome of watermelon (Citrullus lanatus) and resequencing of 20 diverse accessions. Nat. Genet. 45:51-58.

Gusmini, G., R. Song, and T. Wehner. 2005. New sources of resistance to gummy stem blight in watermelon. Crop Sci. 45:582-588.

Hawkins, L.K., F. Dane, and T.L. Kubisiak. 2001a. Molecular markers associated with morphological traits in watermelon. HortScience 36:1318-1322.

Hawkins, L.K., F. Dane, T.L. Kubisiak, B.B. Rhodes, and R.L. Jarret. 2001b. Linkage mapping in a watermelon population segregating for fusarium wilt resistance. J. Amer. Soc. Hort. Sci. 126:344350 .

Kou, Y. and S. Wang. 2010. Broad-spectrum and durability: Understanding of quantitative disease resistance. Curr. Opin. Plant Biol. 13:181-185.

Lambel, S., B. Lanini, E. Vivoda, J. Fauve, P. Wechter, K. HarrisShultz, L. Massey, and A. Levi. 2014. A major QTL associated with Fusarium oxysporum race 1 resistance identified in genetic populations derived from closely related watermelon lines using selective genotyping and genotyping-by-sequencing for SNP discovery. Theor. Appl. Genet. 127:2105-2115.

Levi, A., C.E. Thomas, T.C. Wehner, and X. Zhang. 2001. Low genetic diversity indicates the need to broaden the genetic base of cultivated watermelon. HortScience 36:1096-1101. 
Levi, A., P. Wechter, L. Massey, L. Carter, and D. Hopkins. 2011. An extended genetic linkage map for watermelon based on a testcross and $\mathrm{BC}_{2} \mathrm{~F}_{2}$ population. Amer. J. Plant Sci. 2:93-110.

Lv, C., Y. Song, L. Gao, Q. Yao, R. Zhou, R. Xu, and J. Jia. 2014. Integration of QTL detection and marker assisted selection for improving resistance to fusarium head blight and important agronomic traits in wheat. Crop J. 2:70-78.

Martyn, R.D. 2014. Fusarium wilt of watermelon: 120 Years of research. Hort. Rev. 42:349-442.

Martyn, R.D. and D. Netzer. 1991. Resistance to races 0, 1, and 2 of fusarium wilt of watermelon in Citrullis sp. PI 296341-FR. HortScience 26:429-432.

Maxted, N., B. Ford-Lloyd, S. Jury, S. Kell, and M. Scholten. 2006. Towards a definition of a crop wild relative. Biodivers. Conserv. 15:2673-2685.

McGregor, C.E. and V. Waters. 2013. Pollen viability of $F_{1}$ hybrids between watermelon cultivars and disease resistant, infra-specific crop wild relatives. HortScience 8:1428-1432.

Meru, G.M. 2014. Genetic mapping of resistance to fusarium wilt and seed oil traits in watermelon. PhD Diss., Univ. Georgia, Athens.

Meru, G. and C. McGregor. 2016. Genotyping by sequencing for SNP discovery and genetic mapping of resistance to race 1 of Fusarium oxysporum in watermelon. Sci. Hort. 209:31-40.

Netzer, D. and R.D. Martyn. 1989. PI-296341, a source of resistance in watermelon to race 2 of Fusarium oxysporum f. sp. niveum. Plant Dis. 73:518 (abstr.).

Orton, W.A. 1907. On methods of breeding for disease-resistance. Proc. Amer. Soc. Hort. Sci. 5:28.

Orton, W.A. 1917. Watermelon diseases. USDA Farmers Bul. 821.

Paris, H.S. 2015. Origin and emergence of the sweet dessert watermelon, Citrullus lanatus. Ann. Bot. 116:133-148.

Ren, Y., D. Jiao, G. Gong, H. Zhang, S. Guo, J. Zhang, and Y. Xu. 2015. Genetic analysis and chromosome mapping of resistance to Fusarium oxysporum f. sp. niveum (FON) race 1 and race 2 in watermelon (Citrullus lanatus L.). Mol. Breed. 35:183.

Robinson, R.W. and D.S. Decker-Walters. 1997. Cucurbits. CAB Intl., Wallingford, UK.

Sabbavarapu, M.M., M. Sharma, S.K. Chamarthi, N. Swapna, A. Rathore, M. Thudi, P.M. Gaur, S. Pande, S. Singh, L. Kaur, and R.K. Varshney. 2013. Molecular mapping of QTLs for resistance to fusarium wilt (race 1) and ascochyta blight in chickpea (Cicer arietinum L.). Euphytica 193:121-133.

Sandlin, K.C., J.M. Prothro, A.F. Heesacker, N. Khalilian, R. Okashah, W. Xiang, E. Bachlava, D. Caldwell, D. Seymour, V. White, E. Chan, G. Tolla, C. White, D. Safran, E. Graham, S.J. Knapp, and C.E. McGregor. 2012. Comparative mapping in watermelon [Citrullus lanatus (Thunb.) Matsum. et Nakai]. Theor. Appl. Genet. 125:1603-1618.

Shapiro, S.S. and M.B. Wilk. 1965. An analysis of variance test for normality (complete samples). Biometrika 52:591-611.
Sowell, G. 1975. An additional source of resistance to gummy stem blight in watermelon. Plant Dis. Rptr. 59:413-415.

Sowell, G.J., B.B. Rhodes, and J.D. Norton. 1980. New sources of resistance to watermelon anthracnose. J. Amer. Soc. Hort. Sci. 105:197-199.

Strange, E.B., N. Guner, Z. Pesic-Van Esbroeck, and T.C. Wehner. 2002. Screening the watermelon germplasm collection for resistance to Papaya Ringspot Virus Type-W. Crop Sci. 32:13241330.

Syngenta Seeds Inc. 2009. Watermelon 'SP-4'. U.S. Dept. Agr., Plant Variety Protection No. 200700023. 20 Sept. 2016. <http://www.arsgrin.gov/cgi-bin/npgs/pvp/showpvp.pl?pvpno=200700023 $>$.

Tetteh, A.Y., T.C. Wehner, and A.R. Davis. 2010. Identifying resistance to powdery mildew race $2 \mathrm{~W}$ in the USDA-ARS watermelon germplasm collection. Crop Sci. 50:933-939.

Thies, J.A. and A. Levi. 2007. Characterization of watermelon (Citrullus lanatus var. citroides) germplasm for resistance to rootknot nematodes. HortScience 42:1530-1533.

U.S. Department of Agriculture (USDA). 2016. National Plant Germplasm System, The Germplasm Resources Information Network. 13 July 2016. <http://www.ars-grin.gov/>.

Voorrips, R.E. 2002. MapChart: Software for the graphical presentation of linkage maps and QTLs. J. Hered. 93:77-78.

Wang, S., C.J. Basten, and Z.B. Zeng. 2011. Windows QTL Cartographer 2.5. Dept. Statistics, North Carolina State Univ., Raleigh.

Wechter, W.P., C. Kousik, M. McMillan, and A. Levi. 2012a. Identification of resistance to Fusarium oxysporum $\mathrm{f}$. sp. niveum race 2 in Citrullus lanatus var. citroides plant introductions. HortScience 47:334-338.

Wechter, W.P., C.S. Kousik, M.L. McMillan, M.W. Farnham, and A. Levi. 2012b. Three improved Citrullus lanatus var. citroides lines USVL246-FR2, USVL252-FR2, and USVL335-FR2, with resistance to Fusarium oxysporum f. sp niveum race 2. Phytopathology 102:133 (abstr.).

Zhang, X. and B. Rhodes. 1993. Inheritance of resistance to races 0, 1, and 2 of Fusarium oxysporum f. sp. niveum in watermelon (Citrullus sp. PI 296341). Cucurbit Genet. Coop. Rpt. 16:77-78.

Zhao, J., H.C. Becker, D. Zhang, Y. Zhang, and W. Ecke. 2005. Oil content in a European $x$ Chinese rapeseed population: QTL with additive and epistatic effects and their genotype environment interactions. Crop Sci. 45:51-59.

Zhou, X.G. and K.L. Everts. 2001. First report of the occurrence of Fusarium oxysporum f. sp. niveum race 2 in commercial watermelon production areas of Maryland and Delaware. Plant Dis. $85: 1291$

Zhou, X.G., K.L. Everts, and B.D. Bruton. 2010. Race 3, a new and highly virulent race of Fusarium oxysporum f. sp. niveum causing fusarium wilt in watermelon. Plant Dis. Rpt. 94:9298. 